\title{
USOS DEL PASADO: MEMORIAS EN TORNO A LA "REVOLUCIÓN LIBERTADORA” EN UNA LOCALIDAD DE LA PROVINCIA DE CÓRDOBA, ARGENTINA
}

\section{Uses of the past: memories about the "Liberating Revolution" in a city of the province of Córdoba, Argentina}

\author{
Vanesa Garbero* \\ https://orcid.org/0000-0001-8774-9353
}

\section{Resumen}

Este artículo analiza las memorias de los vecinos de la localidad de Malagueño, provincia de Córdoba, en torno a la autodenominada Revolución Libertadora (1955-1958) y los usos de ese pasado para modelar ciertas representaciones socio-políticas y afectivas cuyas resonancias se extienden hasta la actualidad. Para ello, se desarrolló una estrategia de investigación cualitativa basada en entrevistas en profundidad a vecinos, en su mayoría, contemporáneos a los hechos de violencia política y en fuentes secundarias. El trabajo muestra que estos recuerdos ocupan un lugar predominante en la historia oral local, sus evocaciones guardan nitidez y tienen potencia para explicar la construcción de imaginarios que otorgan sentido a los conflictivos órdenes políticos y a las construcciones contingentes de las identidades políticas.

$<$ Memorias $><$ Usos del pasado $><$ Revolución Libertadora $><$ Desperonización $>$

\begin{abstract}
This article analyses the memories of the neighbours of Malagueño, province of Córdoba, around the so called Revolución Libertadora (1955-1958) and the uses of that past to shape certain socio-political and affective representations, whose echoes still remain in the present day. In order to do so, a qualitative research strategy was developed, based both on in-depth interviews with neighbours -most of them, contemporaries of the events of political violence- and secondary sources. The work shows that these memories occupy a predominant place in the local oral history. Their evocations are sharp and have the power to explain the construction of imaginaries that grant sense to the conflicting political orders and the contingent constructions of the political identities.
\end{abstract}

$<$ Memories $><$ Uses of the past $><$ Liberating Revolution $><$ De-peronization $>$

Recibido: 22/04/2020//Aceptado: 14/10/2020

\footnotetext{
* Centro de Estudios Avanzados de la Facultad de Ciencias Sociales de la Universidad Nacional de Córdoba (UNC) y Centro de Investigaciones y Estudios sobre Cultura y Sociedad (CONICET y UNC), Argentina, vanegarbero@yahoo.com.ar
} 
Garbero. Usos del pasado: memorias en torno a la "Revolución Libertadora" en una localidad de la provincia de...

\section{Introducción}

En las memorias de los/as vecinos/as adultos de Malagueño (provincia de Córdoba, Argentina $)^{1}$ emerge con intensidad la autodenominada Revolución Libertadora (1955-1958), golpe militar que derrocó al presidente constitucional Juan Domingo Perón (1946-1952 y 1952-1955) de su segunda presidencia. Estos recuerdos tienen mayor pregnancia en la historia oral de la localidad que aquellos correspondientes a otros golpes de Estado como la última dictadura cívico-militar (1976-1983) aún cuando esta sea más cercana en el tiempo y coincida con el funcionamiento del ex centro clandestino de detención La Perla, situado enfrente a la localidad. ${ }^{2}$

En la primavera de 1955, Malagueño quedó en medio de los enfrentamientos entre los rebeldes y los leales a Perón. Los/as vecinos/as recuerdan que el pueblo en su totalidad se movilizó e involucró de una u otra manera; la división existente entre amigos, familiares y vecinos peronistas y antiperonistas adquirió matices de violencia, enfrentamiento y persecución; e inició un proceso de desperonización de una sociedad mayoritariamente identificada con el peronismo. ${ }^{3}$ En tal sentido, este trabajo se propone recuperar y analizar las memorias de los/as vecinos/as de la localidad de Malagueño en torno al golpe de 1955 y los usos de ese pasado en el presente. Es de interés, también, comprender los motivos de la pregnancia de esos recuerdos, los hechos que tuvieron lugar el 16 de septiembre de 1955 y los días inmediatamente posteriores, las divisiones y los resquemores que provocó en la pequeña localidad desde aquel entonces hasta la actualidad. Se sostiene que estas memorias resultan útiles a los/as entrevistados/as para explicar y comprender el presente y la historia política de su localidad. Además, se muestra que este golpe de Estado significó la imposición de un nuevo orden político que sería decisivo para disciplinar a la población, reorganizar el espacio público y reconfigurar los límites de las construcciones identitarias políticas.

\footnotetext{
${ }^{1}$ Malagueño es una ciudad de 13.102 habitantes -según censo de Población, Hogares y Viviendas 2010-, está situada al sudeste del departamento de Santa María, provincia de Córdoba, entre las ciudades de Córdoba y Villa Carlos Paz, frente a los terrenos del Ejército. Su historia está ligada desde su comienzo con la actividad minera. Si bien la explotación informal de las canteras en la zona se retrotrae a fines del siglo XVI, recién se constituyó como pueblo en 1886 alrededor de su principal actividad económica relacionada con la extracción de piedra caliza y, a partir de ello, la producción de cal. El 9 de diciembre de 1999, el Concejo Deliberante aprobó por unanimidad la declaración de Malagueño como ciudad (Ordenanza $N^{\circ}$ 679/99) debido al crecimiento demográfico y habitacional de esa última década. Para conocer sobre las corrientes migratorias de malagueño entre 1900-1930 puede verse Sincich (2002).

2 El ex Centro Clandestino de Detención Tortura y Exterminio La Perla fue, después de la Escuela de Mecánica de la Armada (ESMA) y Campo de Mayo, el tercer centro clandestino más grande de la Argentina y desde donde se organizó la actividad represiva ilegal de toda la provincia entre 1976 y 1978.

3 Estos procesos políticos-sociales tuvieron correlato a nivel nacional y provincial. "La desperonización fue marco y contenido de acciones gubernamentales -entre los años ' 55 al ' 56 y embebidas de una obsesiva persecución al peronismo-, puestas en marcha por la autollamada Revolución Libertadora" (Pécora, 2016, p. 36) en pos del "saneamiento de la política" e "ideario democrático" que profesó el régimen militar. Sin embargo, no es posible definir de modo unívoco a las ideas, políticas y métodos para llevar a cabo la desperonización de la sociedad y del espacio público porque la estrategia adquirió matices y contenidos diferentes durante los gobiernos de facto de Lonardi y Aramburu, tornándose más radicalizada con el segundo. Para ver las variaciones durante ambos gobiernos de facto, las ideas y sentimientos en las que se fundamentaron y las políticas que se dispusieron en de ello véase Spinelli (2011).
} 
Desde mediados de los años veinte del siglo pasado, Halbwachs (2004, 2011), el pionero de los estudios de la memoria en clave social, estableció que los individuos recuerdan en grupos delineados en el espacio y tiempo que, mediante marcos sociales específicos, les proveen sentido a sus experiencias. ${ }^{4}$ De su propuesta se derivan varios supuestos fundamentales que guían hasta hoy el campo de estudios sobre la memoria social. En primer lugar, el pasado es una reconstrucción que se realiza desde el presente y allí encuentra los principios de selección, descripción y narración. En segundo lugar, establece el carácter selectivo de la memoria como una de sus propiedades fundamentales, por lo tanto, no se podría recuperar la totalidad del pasado tal cual lo hemos experimentado sino aquello que guarda relación con las preocupaciones, la visión del mundo y percepción del presente compartidas grupalmente. En tercer lugar, propone que la memoria es colectiva fruto de marcos o cuadros sociales -el tiempo, el espacio y el lenguaje y de modo particular la clase, la familia y la religión- que enmarcan las memorias individuales $\mathrm{y}$, por consiguiente, son portadoras de representaciones, necesidades y valores de diversos grupos sociales. En cuarto lugar, entiende que no existe una memoria colectiva única, sino una pluralidad de memorias dada la multiplicidad de grupos.

Otros autores (Pollak, 2006; Jelin, 2002; Vezzetti, 2003; Rabotnikof, 2007; Todorov, 2000, entre otros) recuperaron los desarrollos de Halbawachs y aportaron nuevas perspectivas y lecturas, particularmente, en cuanto a las disputas y los conflictos de las memorias, las luchas de poder, reclamos, mutaciones en qué, cómo y cuándo se rememora, pluralidad de grupos de actores en conflicto que hacen distintos usos de las memorias y compiten por los sentidos del pasado para legitimar su situación presente-futura. Si bien, el pasado no se puede cambiar, sí es posible redefinir el sentido o significado de los acontecimientos (Ricoeur, 1999). Para ello, se disputan en el espacio público diferentes grupos que buscan "establecer/ convencer/ transmitir una narrativa, que pueda llegar a ser aceptada" (Jelin, 2002, p. 39). Estas luchas que se libran por otorgarle el valor de verdad a las versiones de la historia y volverlas dominantes han sido monopolizadas por diferentes grupos a lo largo del tiempo (Lorenz, 2002).

A los fines de este artículo, dado que se aborda el ' 55 a partir de las memorias vecinales, se privilegia el análisis de lo que Michael Pollak (2006) denominó "memorias subterráneas", es decir, aquellos sentidos sobre el pasado construido por grupos marginalizados o minoritarios con relación a las rememoraciones que se sostienen desde los centros de poder. Son memorias que no resultan "ganadoras" o predominantes en los espacios públicos y por lo general no se encuentran contenidas en las versiones historizadas del pasado. Da Silva Catela (2010) afirma que las memorias locales puede ser entendidas como subterráneas porque no tienen los capitales para imponer su sentido de la rememoración en el espacio público. ${ }^{5}$

\footnotetext{
4 Para esbozar un enfoque histórico y revisar las teorías sociológicas sobre el concepto de memoria social de Halbwachs a la actualidad puede verse Olick y Robbins (1998). Para un análisis de la memoria en la cultura contemporánea véase Huyssen (2001).

5 Para una distinción entre memorias dominantes, locales y de-negadas véase Da Silva Catela (2010).
} 
Garbero. Usos del pasado: memorias en torno a la "Revolución Libertadora" en una localidad de la provincia de...

Pollak si bien retoma varios aspectos de la propuesta de Halbwachs, marca un giro en el análisis para preguntarse por "los procesos y actores que intervienen en el trabajo de constitución y formalización de la memoria" (Pollak, 2006, p. 18). Es decir, que desde una perspectiva constructivista se va a interesar en analizar cómo se construyen y solidifican las memorias y quienes intervienen en su conformación. Su abordaje:
"acentúa el carácter destructor, uniformante y opresor de la memoria colectiva nacional. Por otro lado, esas memorias subterráneas prosiguen su trabajo de subversión en el silencio y de una manera casi imperceptible afloran en momentos de crisis a través de sobresaltos bruscos y exacerbados" (Pollak, 2006, p. 18).

Este trabajo se inscribe en la investigación realizada para la tesis doctoral que atiende la relación entre las políticas públicas de memoria que delimitan y recrean los ex Centros Clandestinos de Detención Tortura y Extermino La Perla y Campo de la Ribera como espacios para la memoria y la producción de sentidos, representaciones y conocimientos que circulan en sus entornos vecinales más próximos acerca del terrorismo de Estado y de estos sitios en particular. Los/as vecinos/as de Malagueño fueron seleccionados porque formaban parte del entorno vecinal más próximo a $\mathrm{La}$ Perla, y si bien, la preocupación inicial estuvo centrada en las memorias sobre la última dictadura cívico-militar y en La Perla, el trabajo de campo demostró la recurrencia y preminencia de las memorias vecinales en torno al golpe de 1955, esto condujo a redirigir la atención en este acontecimiento y a profundizar en él.

Para eso se combinó diversas técnicas de recolección de datos propias de la metodología cualitativa y se examinó un amplio corpus de fuentes. A los fines descriptivos de los aspectos metodológicos directamente relacionados con este artículo, se destaca el uso de la entrevista en profundidad como como técnica principal de recolección de datos que, por su cualidad dialógica (Merlino, 2012), posibilitó orientarlas en función de los objetivos de la investigación, a la vez que permitió la emergencia de significaciones no previstas inicialmente. El universo de los/as entrevistados/as aquí referenciados lo conformaron vecinos/as adultos de Malagueño contemporáneos a los hechos de violencia política narrados y, en menor proporción, vecinos/a que si bien no habían nacido en 1955, sus padres $\mathrm{y} / \mathrm{o}$ familiares les transmitieron activamente sus experiencias y vivencias.

La categoría vecino/a "se conforma en un entramado relacional, social e históricamente específico. Dicho entramado se constituye en y a partir de un espacio social, el barrio o pequeña localidad, que los propios vecinos construyen y delimitan en sus prácticas cotidianas" (Bertotti, 2014, p. 2). Durante el trabajo de campo surgió por parte de los/as vecinos/as entrevistados/as la preocupación por el anonimato, por lo tanto se decidió utilizar nombres ficticios. Se acompaña el análisis con referencias de fragmentos de las entrevistas realizadas. Los criterios para trascribirlos fueron: respetar textualmente lo dicho por el/la entrevistado/a, sus dichos se representarán siempre entre comillas, en cursiva y para las citas largas se utilizará el formato especial indicado por 
las normas de citación. Junto a los fragmentos de las entrevistas se mostrarán nombre ficticio, referencia al lugar de morada, edad y fecha de realización de la entrevista.

El enfoque de muestreo fue no probabilístico y dirigido según la lógica del análisis que implica la codificación abierta, axial y selectiva de los datos (Strauss y Corbin, 2002). Para identificar los elementos muestrales de Malagueño se realizó entrevistas exploratorias a los trabajadores del Espacio de Memoria y a informantes claves de la localidad. A la vez, esos informantes claves nos contactaron con otros vecinos, tornándose un muestreo por "bola de nieve o de cadena" (Vieytes, 2004). En este sentido, desde julio de 2015 a marzo de 2017, la muestra alcanzó 23 entrevistas a vecinos/as de Malagueño, las cuales conformaron el corpus principal de análisis de este artículo. ${ }^{6}$

También, se examinaron un conjunto de fuentes secundarias como las producciones audiovisuales y escritas centradas en las memorias vecinales sobre el pasado reciente. Puntualmente, este escrito retoma los archivos del programa de televisión “Malagueño hacia el 2000” (Programa N 63, Malagueño: Canal 4, Mundo visión, 1993) y una serie de testimonios que forman parte del archivo audiovisual del programa de televisión y periódico local denominado Visión Local. Los fragmentos de testimonios aquí citados son referenciados con los datos de los/as vecinos/as tal cual aparecen en los archivos porque son de consulta y circulación pública. Además, se consultaron los diarios La Voz del Interior y Los Principios del mes de septiembre de 1955 y datos estadísticos socio-demográficos provenientes de la Dirección General de Estadística y Censos de la Provincia de Córdoba. Se averiguó la existencia de fuentes periodísticas escritas locales para el período que aquí se analiza y el resultado fue negativo. Esto reforzó la importancia de las fuentes orales y la memoria para reconstruir esos eventos a escala local, teniendo en cuenta que la historia oral prioriza la subjetividad y los sentidos de los hechos construidos por los hablantes. Portelli (1991, p. 42) indica que "Las fuentes orales nos dicen no sólo lo que hizo la gente sino lo que deseaba hacer, lo que creían estar haciendo y lo que piensan que hicieron".

El escrito se compone de tres apartados analíticos. El primero se dedica a las memorias vecinales en torno al levantamiento militar y a las repercusiones a nivel local. Son las memorias de las primeras horas caóticas y los días inmediatamente posteriores al golpe de Estado. El segundo apartado reconstruye la reconfiguración de cierta cotidianidad durante la dictadura implantada y focaliza en los rasgos que asumió el proceso de desperonización en la localidad. El tercero, plantea algunas repercusiones de la "Revolución Libertadora" en la corta historia política democrática de la localidad, a la vez que recorre de modo historiográfico sus principales acontecimientos. Finalmente, se retoman los aspectos centrales desarrollados para responder a los objetivos propuestos en este artículo.

\footnotetext{
${ }^{6}$ La investigación doctoral debido a sus objetivos se extendió desde marzo de 2012 a marzo de 2017, la muestra alcanzó las 74 entrevistas e incluyó no solo a los vecinos de Malagueño, sino también a vecinos de los barrios aledaños a Campo de la Ribera -Maldonado, Müller y Bajada San José. También se entrevistó a los trabajadores de los espacios de memoria La Perla y Campo de la Ribera y a trabajadores del Archivo Provincial de la Memoria.
} 
Garbero. Usos del pasado: memorias en torno a la "Revolución Libertadora" en una localidad de la provincia de...

\section{El golpe de Estado del 55 a escala local}

La provincia de Córdoba fue el epicentro de insurrección cívico-militar autodenominada Revolución Libertadora que contó con el apoyo del conjunto del arco político partidario y la oposición eclesiástica y militar al gobierno peronista. Las condiciones de índole política y religiosa que confluyeron en que la provincia sea el escenario neurálgico son analizadas y sintetizadas por Blanco (2014, p. 159) de la siguiente manera:

"La rutinización política del peronismo local con afinidades católicas y carente de autonomía; la formación del Partido Demócrata Cristiano y la reactivación del asociacionismo católico juvenil y profesional como respuesta defensiva (y posteriormente ofensiva) a lo que se percibía como un intento de peronización de la sociedad, sumadas a la disposición golpista de partidos opositores y de numerosa oficialidad joven del ejército y de la aeronáutica, en una guarnición militar importante, constituyeron una combinación explosiva que eclosionó con el golpe de Estado de septiembre de 1955".

La "participación del conjunto de la clase política local" y "la intervención de los civiles, restringida en una principio a reducidos grupos de activistas, que tendió a masificarse con los repartos de armas (...)" constituyeron especificidades del golpe de 1955 en esta provincia (Tcach, 2006, p. 265). ${ }^{7}$

El 15 de septiembre de 1955 por la noche, el general Eduardo Lonardi -líder de la sublevación- tomó la Escuela de Artillería y la Escuela de Aviación Militar de Córdoba y, arrestó los oficiales y suboficiales leales. ${ }^{8}$ Los combates contra el Regimiento de Infantería -leales al gobierno- se produjeron pocas horas después. La prensa de la época testifica que desde madrugada del 16 de septiembre, en el campo que ocupan las unidades del ejército, camino a La Calera, se enfrentaban efectivos pertenecientes a la Escuela de Artillería y a la Escuela de Infantería "R. 13" y los estampidos de las armas se escuchaban hasta en la ciudad de Córdoba. ${ }^{9}$ La localidad de Malagueño está ubicada

\footnotetext{
7 El 21 de septiembre la provincia de Córdoba fue proclamada por el presidente de facto Lonardi como "Capital Provisional de la República", pasó a ser exaltada como "Córdoba La Heroica", "Cuna de la Libertad", "Reducto de la Fe" y "Estandarte de una Nueva Cruzada". Para un análisis histórico de las condiciones que condujeron al golpe de Estado de 1955 haciendo foco en el escenario político cordobés puede verse Blanco (2014) y Tcach (1991; 2006). También, Escudero (2018) y Pécora (2016) han realizado trabajos de reconstrucciones históricas en clave local de la ciudad de Rio Cuarto de la provincia de Córdoba, cuna del golpe de 1955. Yuszczyk (2013) analiza editoriales del Diario cordobés Los principios en apoyó al golpe de 1955 y muestra el rol de los medios en la construcción de los "acontecimientos" históricos.

8 Los oficiales y suboficiales detenidos y alojados en dependencias militares fueron: el director de la Escuela de Militar de Aviación, brigadier Raúl Óscar Lacabanne, el director de la Escuela de Oficiales de Aeronáutica, Comodoro Alberto Machado y el Jefe del Servicio de Informaciones de Aeronáutica Vice comodoro Ernesto Bartó (Los Principios, sábado 17 de septiembre de 1955).

9 Los Principios, sábado 17 de septiembre de 1955 y La Voz del Interior, sábado 17 de septiembre de 1955, p. 3.
} 
en la zona de los enfrentamientos, frente al terreno militar que conecta con la ciudad de La Calera y a 7 km de la Escuela de Aviación Militar de Córdoba.

Los entrevistados recuerdan que ese 16 de septiembre de 1955 tomaron conocimiento por la radio que los generales Eduardo Lonardi y Dalmiro Videla Balaguer -comandante de la IV región militar con asiento en Río Cuarto- se levantaron en armas contra Perón. ${ }^{10}$ Unas horas después de ello, Malagueño quedó en medio de un enfrentamiento entre los "rebeldes o golpistas" y los "leales" a Perón. Desde la Escuela de Artillería Aerotransportada y Paracaidista -ubicadas en el camino a La Caleracomenzaron a disparar morteros, cañones y bombas aéreas hacia una columna que venía avanzando desde San Luis y se encontraba en las inmediaciones de La Lagunilla, un lugar próximo a Malagueño. Entre los/as entrevistados/as predomina la idea que los enfrentamientos tenían como objetivo "sacar a Perón". ${ }^{11}$

En las proximidades de La Lagunilla estaban los leales a Perón que tenían órdenes de aplacar las tropas rebeldes que se concentraban en el regimiento militar, en la fábrica militar de aviones y en la Escuela de Aviación Militar. Malagueño quedó en medio de la zona de fuego y antes de la primera bomba -que aconteció alrededor de las 17 horas e impactó en el antiguo matadero según los recuerdos vecinales- la gente recibió órdenes de la policía de abandonar los hogares y retirarse al sector de las canteras de cal y granito - ubicadas al oeste del centro de la ciudad- para refugiarse en los túneles. ${ }^{12}$ Muchos vecinos se movilizaron a las canteras, otros se agruparon y se encerraron en los sótanos de algunas viviendas. A continuación, se transcriben los relatos de tres vecinos sobre ese día:

"Camilo: Estaba jugando yo con mi primo, corriendo con la pelota, llenos de tierra como siempre, calculá que soy del $49 \ldots$ en el 55 habré tenido 7, 6 años, y empezamos a ver unos boom, boom, así como si fuera a llover y hubiera unos rayos en el cielo, y sale la madre de adentro, mi tía Ruth... "Chachino,

\footnotetext{
${ }^{10}$ La prensa da cuenta de una serie de comunicados que fueron difundidos por las emisoras locales la mañana del 16 de septiembre, alrededor de las 9.30 el primero y a las 11.30 el segundo. En ambos se aseguraba que eran dominados los focos de rebelión que se habían levantado contra "la constitución y las autoridades legalmente constituidas". A las 12.30, en el tercer comunicado, el gobierno de la provincia aconseja a la población retirarse a sus hogares y permanecer en ellos para evitar incidentes ( $\mathrm{La}$ voz del interior, sábado 17 de septiembre de 1955, p. 3).

${ }^{11} \mathrm{Si}$ bien la perspectiva de este escrito se focaliza en aquello que recuperan las memorias vecinales, en algunos tramos está presente la tensión entre la historia y la memoria. Pierre Nora $(2008$, p. 20) puntualiza las diferencias entre ambas de la siguiente manera: "La memoria es la vida, siempre llevada por los grupos vivientes y a este título, está en evolución permanente, abierta a la dialéctica entre el recuerdo y la amnesia, inconsciente de sus deformaciones sucesivas, vulnerable a todas las utilizaciones y manipulaciones, susceptible a largas latencias y repentinas revitalizaciones. La historia es la reconstrucción, siempre problemática e incompleta, de lo que ya no es". Esta última tiene objetivos diferentes, utiliza una metodología determinada, saberes técnicos y toma a la memoria como objeto o como una fuente más a cotejar con otras.

${ }^{12}$ En ese entonces el acceso a las canteras era menos restringido pero, fuera de este acontecimiento, era un lugar frecuentado por los trabajadores, no por la población en general. En la actualidad, los túneles ya no existen, solo quedó una profunda depresión en la zona.
} 
Garbero. Usos del pasado: memorias en torno a la "Revolución Libertadora" en una localidad de la provincia de...

ándate a tu casa, me corría a mí...vos, Coco pasá a lavarte acá, carajo, sinvergüenza" “Qué pasa?” "Que hay un lío bárbaro" no sabía explicar ella, así que me corrió acá a mi casa, y de allá venía, y cuando venía llegando se sentía pum, pum, unos cañonazos bárbaros y yo veía a la gente, un vecino, subidos arriba del techo... mi mamá que venía corriendo "vení, para acá, vos, dónde andás?", agarró, me puso debajo de la canilla, me cepillaba, me cambiaba la ropa..."¿adónde vamos a ir con todo este lio?" decía yo, y yo veía que la gente venía por la calle con unas valijas, otro con bolsas... "vamos Ramón -le gritaban a mi papá- vamos para el lado de las canteras porque vienen tirando de allá, vienen cañoneando, nos van a hacer pedazos". Ahí tomé conciencia yo de lo que estaba pasando, "¿papi, qué pasa, hay una guerra?" decía yo... te imaginás vos... "sí, dice, hay una"...esperá vos...y mi vieja pobrecita, yo me acuerdo, agarra una bolsa y metía un pedazo de queso y un pedazo de dulce y un pan adentro, y agarró un poco de ropa, puso en otro lado y nos fuimos para allá. Claro, atrás de la iglesia había unas canteras, las canteras de cal, en un túnel, ahí metidos, y yo decía: ¿qué haremos acá? y se sentían los aviones que pasaban, los cañonazos (...)"13.

"Desde el 1955 fue algo tremendo para nosotros porque nunca había ocurrido esto aquí. Para todos, personas más antiguas que yo, ¿no cierto? También decían que nunca, nunca había pasado esto tan grave. De ahí en más, fue cuando mi hijo se subió al techo y entonces vio que eran de la Fuerza Aérea que tiraban bombas. Entonces cayó a dos cuadras de mi casa, primero. La gente se iba para allá, a refugiarse, para Montevideo [barrio que existía en aquel entonces cerca de las canteras, algunas de las viviendas tenían sótanos], pensando que eso era lo bueno. Pero yo pienso que no, que estábamos equivocados, tenía que estar cada uno en su casa. Pero en la desesperación, la gente que jamás había esto, todo el mundo corría par allá (...)"14.

“(...) recuerdo que estaba con mi mamá en el patio -mirá, ahora me recuerdo- y teníamos una radio de esas grandes marrones y estábamos escuchando radio, mi mamá estaba creo que lavando y yo sentí que mi madre dijo que anunciaron en la radio de que se había declarado la revolución. Y sentimos los aviones nosotros y llegó la policía avisando que teníamos que irnos urgente porque iban bombardear el pueblo. Entonces,

\footnotetext{
${ }_{13}^{13}$ Entrevista de la autora a Camilo, vecino de Malagueño, 67 años, 8 de noviembre de 2016.

${ }^{14}$ Entrevista realizada por Mario San Martín a Rosario Maldonado de Nieto, vecina de la Malagueño, para el programa de televisión "Malagueño hacia el 2000", 1993.
} 
mi mamá alzó algunas cosas (...) nos acompañaron hasta la cantera y había unos túneles, unos túneles largos. Y había mucha gente ahí en esos túneles... Luego como no teníamos como hacer camas, cortaban un yuyo que se llamaba -no me olvidé nunca- Duraznillo, que había mucha cantidad alrededor y se hacían estas camas para, para acostarse. No me acuerdo cuántos días estuvimos (...)"15.

En las canteras se improvisaron camas, se organizó una olla popular para la primera cena mientras reinaba un clima tenso en el cual se enfrentaban diferentes interpretaciones y posiciones frente a lo que estaba ocurriendo. Dos de los entrevistados recuerdan que una mujer - "la esposa de Juan Romero"- tuvo mellizos en la cantera y luego del parto falleció. El tiempo que pasaron refugiados en las canteras resulta impreciso pero varía de uno a tres días, y esto es consecuente con las decisiones que tomaron las familias y los distintos criterios que surgieron en esos momentos sobre las ventajas y desventajas de permanecer en un lugar descampado. Los recuerdos mantienen muy vivaz las sensaciones de miedo, desconcierto y angustia.

Los vecinos que hicieron el servicio militar en las dependencias de las Fuerzas y sus familiares recuerdan que ese día quienes fueron identificados con el peronismo y quienes se expresaron contra el golpe fueron apresados y, los demás, se vieron obligados a participar en el lanzamiento de explosivos hacia el sur, aun existiendo la posibilidad de herir a sus propios parientes de Malagueño. En relación a ello, véase los siguientes testimonios:

"Para nosotros fue muy angustioso aquellos momentos que pasamos porque en ese año, mi hermano estaba haciendo el servicio militar en la Marina. Además, teníamos un primo que estaba haciendo el servicio militar en el Ejército, estaba en la Escuela de paracaidistas, acá. Te imaginarás que la Marina estaba no plegada a la Revolución entonces tenían que enfrentarse y eso fue, para nosotros, desesperante, para ellos mismos, también, fue angustioso. Además, mi primo, el que estaba aquí en la escuela de paracaidistas tenían órdenes de bombardear para el pueblo, para su pueblo porque él vivía acá y tenía toda su familia acá: padre, madre, hermanos primos que éramos nosotros. (...) Así que para nosotros fue una experiencia muy muy dura y dolorosa en aquella época. Pero felizmente a ninguno de los dos les pasó nada pero queda en el recuerdo, triste recuerdo" 16 .

"En la escuela de aviación hacíamos guardia día de por medio porque ya se estaba esperando el golpe de Estado. El día 15 salimos de guardia con el que era soldado Antonio Rey.

\footnotetext{
${ }^{15}$ Entrevista de la autora a Cristina, vecina de Malagueño, 64 años, 30 de julio de 2015.

${ }^{16}$ Entrevista realizada por Mario San Martín Amanda Fioramonti de Orazi, vecina de Malagueño para el programa de televisión "Malagueño hacia el 2000”, 1993.
} 
Garbero. Usos del pasado: memorias en torno a la "Revolución Libertadora" en una localidad de la provincia de...

Salimos de guardia, entramos al otro día, o sea hacíamos 24 x 24. El día 16 de septiembre íbamos a primera hora para presentarnos al cuartel y en la Fábrica de Paracaídas, que era la fábrica de motos, ahí nos hicieron descender del ómnibus una patrulla militar donde estaba el Capitán Peréz Flojo [sic] y nos hicieron bajar. Y ahí nomás nos pusieron en la camioneta de la aeronáutica y nos llevaron a la Escuela de Suboficiales. Ahí estuve preso hasta el día 18 a la tarde, de septiembre. Nos llevaron a la cárcel de penitenciaría. Éramos soldados del IAME y todo el IAME era peronista en esa época. O sea al ser soldado de Aeronáutica y ser soldado de IAME, directamente nos mandaron a la cárcel"17.

El último entrevistado trae con su relato la composición peronista de IAME (Industrias Aeronáuticas y Mecánicas del Estado) y, en consecuencia, la detención asegurada de los trabajadores por la pertenencia partidaria. La planta industrial funcionaba en las instalaciones del Instituto Aerotécnico, entonces FMA (Fábrica Militar de Aviones), ubicada en las inmediaciones de la localidad de Malagueño. Si bien, la historia de IAME no fue reconstruida por las memorias locales relevadas, su surgimiento, auge y declinación estuvieron relacionados con los gobiernos peronista y el golpe Estado de $1955 .{ }^{18}$ El impacto de la "Revolución Libertadora" fue inmediato, primero cambió los nombres de los vehículos que aludían al gobierno depuesto, detuvo la fabricación del automóvil "El Justicialista" -modelo "Justicialista coupe plástico sport"- y abandonó desarrollos que se proyectaban para impulsar la industria automotriz argentina. Con Pedro Eugenio Aramburu como presidente de facto (noviembre 1955 mayo 1958), el IAME cambió de nombre a DINFIA (Dirección Nacional de Fabricación e Investigación Aeronáutica) y redefinió su actividad, orientándola exclusivamente a las actividades del sector aeronáutico y aeroespacial.

Otro vecino de Malagueño que también hacía el servicio militar en la Escuela de Artillería recuerda de esa noche, la orden que lo despertó a la madrugada para "levantarse urgente", "alinearse", "tomar sus armas" y "apostarse en el lugar de trabajo". Este vecino trabajaba en el taller mecánico, casualmente estaba como chofer de turno en la guardia de la ambulancia, y recuerda que a las 2 de la mañana comenzaron las "bombas y los tiroteos para un lado y para otro". Al día siguiente, recuerda que "desde el lado del Colegio Domingo Savio" también bombardearon con un mortero pero no hubo víctimas

\footnotetext{
${ }^{17}$ Entrevista realizada por Mario San Martín a Antonio Romero, vecino de Malagueño, Archivo Visión Local, 1995.

${ }^{18}$ Las industrias agrupadas bajo ese nombre habían sido creadas por un decreto del gobierno peronista el 28 de marzo de 1952, "con las funciones de investigación, fabricación y reparación de material aeronáutico y la promoción y producción automotriz". Extraído de http://www.clubiame.com.ar/historia. $\mathrm{htm}$, consultado en junio de 2020. IAME estaba integrada por diez fábricas: de Aviones, de Motores de Aviones, de Motores a Reacción, de Instrumentos y Equipos (para aviones y automóviles), de Paracaídas, de Hélices y Accesorios, de Máquinas y Herramientas en el área aeronáutica y de Automóviles, de Tractores, de Motocicletas y de Automóviles.
} 
humanas porque estas bombas cayeron en un corral de caballos cercano. Aún cuando este entrevistado describe algunas tareas que desempeñó durante esa madrugada, los desplazamientos a las Escuelas de Infantería y de Aviación, las distintas maquinarias que condujo, afirmó desconocer el "bando" para cual peleaba en ese momento: "había sido inesperado" y "nadie sabía nada”. Este vecino relata esto último de manera muy sintética y se detiene en un encuentro que tuvo con su madre en medio de una de las jornadas:

"Miguel: (...) En el transcurso del viaje, mi madre estaba ahí en la puerta de la Escuela de Aviación. Pedí autorización al oficial que iba conmigo, quería hablar un momento con ella. Me autorizó, paramos. Y todo quedó bien. (...) mi mamá estaba bastante preocupada porque algunos muchachos se habían hecho una disparada hasta Malagueño a ver los familiares. Mi madre, por supuesto, averiguó por mí. (...) ellos le dijeron a mi madre que no habían tenido ningún contacto, entonces ella se desesperó. ¿En qué forma llegó allá? No lo sé, pero estaba ahí en la Escuela, no la dejaban pasar adentro pero da la casualidad que yo venía de la Escuela de Artillería a la Escuela de Aviación y ahí me encontré con ella.

Mario San Martín: La información de todo lo que acontecía en aquel entonces ¿se lo comunicaban?

Miguel: nada, nada. En absoluto. Ninguna comunicación. No sabíamos para qué bando estábamos peleando. No, no sabíamos... hasta que fue la segunda o tercera noche, ahí el suboficial que estaba a cargo del área motorizada nos informó que era para derrotar al gobierno ${ }^{19}$.

Este es el único testimonio relevado en las entrevistas y los archivos que afirma haber participado entre las fuerzas golpistas, sin denominarlas de este modo. En la reconstrucción que hace de esos eventos, él no se sitúa como corresponsable de las consecuencias, se describe cumpliendo órdenes. No parece haber mediado otro tipo de reflexiones, tampoco años después cuando dio su testimonio para el medio de comunicación local. Sólo al final de su relato, ante la pregunta del entrevistador, apela al deber de las generaciones jóvenes de no repetir estos acontecimientos por lo penoso de las muertes y los heridos. También, su relato ilustra los sentimientos de su madre, quién desde Malagueño, vivió con preocupación el destino de su hijo. En la preocupación de esa madre recreamos una emocionalidad que se reitera entre los otros vecinos/as.

Por otro lado, algunos trabajadores que pertenecían al Sindicato de Obreros de la Cal advirtieron las consecuencias de lo que estaba pasando ese 16 de septiembre e intentaron organizar una fuerza que hiciera frente a los "rebeldes" que estaban en la Escuela de Aviación Militar. Pero resultó un fracaso porque fueron muy pocos los

${ }^{19}$ Entrevista realizada por Mario San Martín a Miguel Jorge Della Vedova, vecino de Malagueño, Archivo Visión Local, 1995. 
Garbero. Usos del pasado: memorias en torno a la "Revolución Libertadora" en una localidad de la provincia de...

que lograron reunirse, muchos de los vecinos ya estaban refugiados en las canteras e instalaciones de la Cantera Malagueño ${ }^{20}$.

En efecto, mientras se peleaba en La Calera y parte de la población de Malagueño estaba refugiada en las canteras o en los sótanos de las viviendas, las radios de Córdoba tomadas por los rebeldes transmitían la proclama firmada por dirigentes de la Unión Cívica Radical (UCR) que convocaba a la rebelión armada para "defender la libertad, la democracia, la justicia y la paz de la familia argentina". Al no contar con Infantería porque esta fuerza permaneció leal al gobierno de Perón, se instó civiles a defender la revolución y "luchar por libertad" para lo cual se los proveyó de armas. Durante la madrugada y la mañana del 16 de septiembre "los cordobeses fueron invocados en su doble condición de ciudadanos y cristianos" (Tcach, 2006, p. 261).

Al igual que en Córdoba y Río Cuarto, en Malagueño se conformaron comandos civiles armados que comenzaron a ocupar las calles. ${ }^{21}$ Pécora señala que estos comandos, tuvieron diferentes formas de organización, "pero cumplieron idénticas funciones de represión y persecución política e ideológica de ciudadanos, dirigentes partidarios y destrucción de elementos de orden simbólico vinculados al peronismo (...)" (2012, p. 264). A nivel local, los entrevistados recuerdan que los militares fueron a la comisaría ubicada frente a la plaza del pueblo, la sumaron para la causa golpista y entregaron armas a los vecinos que querían colaborar “con la revolución”. Fue así que grupos de vecinos recorrieron las calles con armas, amenazado y arengando a los otros identificados con el peronismo. Así lo relata uno de los vecinos:

"Camilo: (...) los golpistas contaron con la colaboración de los civiles. Acá en Malagüeño colaboraron muchos civiles (...) los milicos vinieron a la comisaría que estaba ahí en la plaza, al frente y dejaban armas, dejaban armas para los que querían colaborar, entonces iban estos tipo milicianos.

Entrevistadora: Y que buscaran un arma ¿para qué?

Camilo: Para colaborar en la seguridad, para hacer guardia con ellos, sería para matar a alguno que no pensara como ellos... me acuerdo que había ciertos personajes acá que después quedaron en la historia...era mofa y charra [sic] que se armaban todos, agarraban unas bicicletas que andaban por la calle, todos armados... después le gritaban cosas porque quedó así eso de que estaba siempre esa tirantez...sí, es que había un montón de gente que colaboró con ellos, uno de los que colaboró con ellos pasó a ser después intendente."22

${ }^{20}$ Tomado del relato de Mario San Martín, Programa de televisión "Malagueño hacia el 2000”, 1993.

${ }^{21}$ Los diarios de la época relatan que la vigilancia de las calles de la ciudad de Córdoba estuvo a cargo de civiles, en su mayoría, jóvenes, que se ofrecieron para esa tarea al Comando de la Revolución (véase Los Principios, 19 de septiembre de 1955, también en La Voz del Interior el 20 de septiembre de 1955, p. 4. En este último artículo se incluyen fotografías de civiles patrullando las calles y haciendo guardia en esquinas del centro de la ciudad).

${ }^{22}$ Entrevista de la autora a Camilo, vecino de Malagueño, 67 años, 8 de noviembre de 2016. 
Una semana después del levantamiento militar, el 23 de septiembre de 1955, Lonardi asumió la presidencia provisional de la nación. La sublevación triunfante se autodenominó "Revolución Libertadora" y si bien no había "vencedores o vencidos", según el discurso conciliador del presidente de facto, en Malagueño el antiperonismo encontró las condiciones favorables para su expresión y profundización.

\section{Dictadura y vida cotidiana en Malagueño}

Lonardi se mantuvo sesenta días en el poder, tras un golpe palaciego, asumió la presidencia el general Pedro Eugenio Aramburu el 13 de noviembre de 1955. Según el gobierno militar de Aramburu-Rojas la transición política tenía un prerrequisito que, a la luz de los acontecimientos posteriores, César Tcach (2003, p. 24) señaló como la "ilusión pedagógica" de la Revolución Libertadora y consistía en la reeducación colectiva de las masas peronistas. Esto significaba "la disolución de esa identidad política y su reabsorción gradual por las sedicentes fuerzas democráticas". Ese objetivo estaba basado en una representación particular y parcial del peronismo, al entender que el movimiento se orquestaba por el aparato propagandista de su líder demagógico. Para ello, Aramburu implementó un conjunto de medidas que incluyeron la adjudicación del delito de "traición a la patria" a Perón, disolución del partido peronista e inhabilitación de sus integrantes a cargos públicos, intervención de la Confederación General del Trabajo (CGT), proscripción de la representación gremial a quienes ocuparon cargos a partir de 1952, entre otras (Tcach, 2003, p. 24).

Esas medidas que combinaron censura, persecución y represión encuentran asidero en las memorias de los vecinos de la pequeña localidad de Malagueño:

"A mi marido [miembro de la Comisión del Sindicato de Obreros de la Cal] lo perseguían. Ciertas personas de acá (...) Era perseguido, acusándolo que quería quemar la iglesia, siendo que andaba con nosotros, él no se separó de nosotros. Fue cuando ciertas personas del pueblo, que no tenían las mismas ideas que él lo llevaron, primero a la policía aquí. Vinieron unos oficiales, a los dos días que ya estábamos en la casa (...) Entonces a través de una ventana yo veo que lo venían apuntalando a él. (...) Llegaron y sacaron todo, diciendo que tenía un arma. Jamás usó un arma. Sacaron la ropa del ropero, todo y hallaron la foto de Perón. 'Y esto ¿por qué lo tienen?' y ‘bueno lo tenemos porque nosotros lo queríamos y una foto...'. Mi marido me mandó a callar, que yo no hablara, pero yo le digo que una foto no perjudicaba a nadie. De ahí se lo llevaron a la policía pero después de revolver todo, pensando que había armas (...) siempre custodiaban la casa, no nos dejaban tranquilos después que había terminado todo. Incluso él renunció al sindicato, entregó los papeles, que dicho sea de paso no era nada malo, era por los obreros" ${ }^{23}$.

\footnotetext{
${ }^{23}$ Entrevista realizada por Mario San Martín a Rosario Maldonado de Nieto, vecina de la Malagueño, para el programa de televisión "Malagueño hacia el 2000", 1993.
} 
Garbero. Usos del pasado: memorias en torno a la "Revolución Libertadora" en una localidad de la provincia de...

El testimonio de la entrevistada es expresivo del clima de época y enlaza varios aspectos: la persecución a representantes gremiales peronistas, enfrentamientos entre vecinos del pueblo y la adjudicación de un supuesto delito que asocia los conflictos entre el gobierno peronista y la iglesia católica y que ella puede reconocer que, de fondo, el enfrentamiento era ideológico político. Además, aparece el afecto como justificativo para conservar, aún con riesgo, la fotografía de Perón, cuestión que permite complejizar el imaginario reduccionista militar en torno a la relación de Perón y con sus seguidores. La entrevistada recordó que la persecución a su marido se extendió en el tiempo:

"Y eso duró más o menos por dos meses, si no más. O sea que él tenía que cuidarse. Tenía que cuidarse de no ir al lado que había un boliche. (...) porque seguro que lo llevaban otra vez, preso. Incluso la llave [en la puerta] y atravesábamos una mesa porque teníamos miedo, teníamos miedo. Cuando él se iba a trabajar, ya nos levantábamos porque pensábamos que alguien venía”24.

La proscripción de la representación gremial y persecución a sindicalistas peronistas en la localidad también fue relatada, en primera persona, por otro vecino del Sindicato de Trabajadores de la Carne:

"En octubre me coparon el sindicato los revolucionarios. El de los Caleros ya lo habían tomado, el mío lo tomaron después, recién en octubre. Y de ahí empezó la persecución para nosotros. Yo fui detenido varias veces, perseguido. En ese tiempo éramos todos conocidos los que estaban acá, los que nos perseguían eran todos de acá, del pueblo. Fíjense ustedes que yo salí del trabajo, un día sábado (...) golpean la puerta (...) cuando salgo afuera estaba el Pita Palacios que le llaman, de acá de Malagueño, con una pistola, y con una pistola me apuntó y me llevó a la comisaria. Cuando fui a ahí, después ya lo llevaron a Ruiz, un gran dirigente que ha sido Ruiz, ya no lo tenemos, estaba Brizuela, el Chacho, Piredo, Francisco Piredo, varios y nos llevaron a Córdoba" 25

También otras familias identificadas como peronistas relatan allanamientos a sus viviendas, detenciones y ensañamiento. Sus relatos van reconstruyendo el lugar que tenía la militancia peronista en la localidad. Véase los siguientes relatos:

"Mario San Martín: Malagueño, o algunas familias concretamente, la pasaron mal.

Antonio: sí, sí, claro. La mayoría de las familias. Como era gente toda pobre y eran todas peronistas, estuvieron zumbando.

${ }^{24}$ Entrevista realizada por Mario San Martín a Rosario Maldonado de Nieto, vecina de la Malagueño, para el programa de televisión "Malagueño hacia el 2000", 1993.

${ }^{25}$ Entrevista realizada por Mario San Martín a Rufino Moreno, vecino de Malagueño, Archivo Visión Local, 2002. 
Mario San Martín: fue el caso de su madre.

Antonio: sí, fue el caso de mi madre. Le requisaron toda la casa. A mi hermano también lo detuvieron, junto con Zamora, y varios de la gente de la unidad básica"26.

"Mi papá me contó que habían aparecido unas pintadas con alquitrán. Acá en las paredes de Malagueño. No recuerdo qué decían pero eran 'Perón vuelve', 'Perón', no sé, algo así habrán escrito, ¿no? Y justo mi papá no había tenido nada que ver con esas pintadas, pero en la casa de mi abuela se había usado alquitrán para el techo. Entonces mi papá -porque andaban haciendo requisas, fijándose en las casas- agarró la olla y la enterró en el patio de la casa vecina (...)"27.

“(...) Mi abuela fue la que fundó acá la primera unidad básica peronista. Mi padre comienza la política, porque mi abuela hacía lo mismo (...) En el '55 no eran de los peronistas tranquilos lamentablemente, eran de los peronistas pesados. Cuando se inauguró, por ejemplo -yo te estoy diciendo cosas que yo escuché, que él sinceramente me dijo-armaban bombas en la casa. ¿Te das cuenta? Tenían literatura pesada en la casa. Mi papá y mi abuela eran de esto así: libros que después que... arrasaron cuando les quemaron. (...) la cuestión es que eran de estos locos que fueron en la moto a Córdoba a la inauguración (...) a ponerle una bomba y... Se la pusieron con tan mala suerte de que eran buenos, no eran asesinos, si no que estaban peleando por ideales. Y el tipo que quiso poner la bomba no alcanzó a dejarla porque no sé qué una mujer se cayó o veía que una mujer se iba a acercar mucho a donde estaba, entonces la bomba le explotó en la mano. Y no pudieron hacer lo que tenían planeado hacer, entonces se armó un revuelo, todos salieron huyendo. Ese tipo obviamente que fue apresado, y el resto escapó"'28.

A raíz de ese hecho que tuvo lugar en la ciudad de Córdoba, la entrevistada relató que fuerzas de seguridad allanaron la vivienda donde vivían su padre y abuela en Malagueño, él ya no estaba ahí pero revisaron de forma completa cada rincón y quemaron ahí mismo toda la bibliografía relacionada con el peronismo. Más allá del ámbito local, Spinelli (2011, p. 13) sostiene que "la profundización y sistematización de las políticas desperonizadoras, (...) tuvo como efecto no deseado para los 'libertadores',

\footnotetext{
${ }^{26}$ Entrevista realizada por Mario San Martín a Antonio Romero, vecino de Malagueño, Archivo Visión Local, 1995.

${ }^{27}$ Entrevista de la autora a Julia, vecina de Malagueño, 48 años, 8 de febrero de 2017.

${ }^{28}$ Entrevista de la autora a Verónica, vecina de Malagueño, 40 años, 8 de febrero de 2017.
} 
Garbero. Usos del pasado: memorias en torno a la "Revolución Libertadora" en una localidad de la provincia de...

el surgimiento de la 'resistencia peronista' que ensayó espontáneamente diversas formas de violencia, propaganda y desestabilización política". En Malagueño no se pudieron rastrear relatos de acciones de militancia directa contra el régimen militar, excepto las referencias puntuales, en los dos últimos fragmentos de testimonios recién citados, que refieren a pintadas en las paredes de la localidad y la participación en el intento fallido de colocar un explosivo en Córdoba. En ambos casos, la militancia de sus padres aparece ligada a ideales como la igualdad, la defensa de los trabajadores y la lucha para mejorar su calidad de vida.

En las memorias vecinales asoman situaciones incómodas o de censura que atravesaron quienes tenían fotografías, diarios, libros o cualquier objeto, signo y/o expresión de "propaganda peronista" según el nuevo régimen. Esto guardaba relación con el Decreto de Ley $\mathrm{N}^{\circ} 4.161^{29}$ que en su artículo primero prohibía para todo el territorio nacional "La utilización con fines de afirmación ideológica peronista, efectuada públicamente, o propaganda peronista (...) de las imágenes, símbolos, signos, expresiones significativas, doctrinas, artículos y obras artísticas (...)”. Ese decreto prohibía el uso de la fotografía retrato o escultura del viejo líder, de los funcionarios peronistas o sus parientes, tampoco podía utilizarse el escudo ni la bandera peronista ni pronunciarse los términos "peronismo", "peronista", "justicialismo", "justicialista", "tercera posición", la marcha peronista ni los discursos del ex presidente Juan Domingo Perón y de Eva Perón, así como tampoco "el nombre propio del presidente depuesto o el de sus parientes". A pesar de este detallado listado prohibitivo encontramos entre algunos/as entrevistados/as pequeñas resistencias al régimen militar que consistían en esconder esos objetos o elementos de identificación partidaria o sortear los controles con diferentes estrategias durante las requisas de sus viviendas o ante las miradas curiosas de otros vecinos. No se han relevado historias locales de vecinos/as que hayan tenido que afrontar las penas de cárcel o multa económicas establecidas en el artículo tres el Decreto Ley $\mathrm{N}^{\circ} 4.161$ para los infractores.

Las nuevas condiciones políticas trastocaron el espacio público en lo simbólico y afectivo. Los/as vecinos/as recuerdan que fue arrancado y arrastrado por las calles del pueblo el busto de Evita que estaba ubicado en la plaza principal. "La importancia de esta plaza es central en la fisonomía del poblado de ese entonces hasta la actualidad. Está situada estratégicamente, frente a la Estación Ferroviaria, al Cerro Grande y a los hornos para quemar cal" ${ }^{30}$ Este tipo de acciones pretende cierta eficiencia simbólica en la construcción de la realidad e imponer una visión y división del mundo social (Bourdieu, 1985). La presencia, o la ausencia en este caso, de personajes, imágenes y símbolos del pasado colectivo es utilizada para legitimar el poder (Balandier, 1994) y, por lo tanto, podríamos pensarla funcional a la construcción del imaginario político buscado por el régimen militar.

\footnotetext{
${ }^{29}$ InfoLeg, Argentina, 5 de marzo de 1956.

${ }^{30}$ Información extraída de Sincich, Sonia “Malagueño Cumple 123 años”, Infoguía Malagueño, el portal de nuestra ciudad, 28 de julio de 2009. Disponible en: http:/www.infoguiamalagueno.com.ar/noticiasdetalle.php?noticia=54 Consultada por última vez en abril de 2020.
} 
Ante el "trabajo de encuadramiento" de la memoria para "definir y reforzar sentimientos de pertenencia y fronteras sociales" (Pollak, 2006, p. 25), la historia oral pone en evidencia los límites de ese trabajo. Una vecina entrevistada recordaba:

"Uno de los actos que a la gente le resultó muy violento fue sacar el busto de Eva Perón de la plaza, ultrajarlo de alguna manera, y lo enterraron. Y muchas provocaciones en la calle... Mi papá me mencionaba un cura [León Nespoli], estaba en el jeep con la gente armada, con los antiperonsitas, con los fusiles. Nespoli andaba con un bastón siempre y tenía un estilete dentro del bastón. (...) mi papá estaban en un bar cerca de la iglesia con un grupo de amigos y el cura este se paraba ahí a provocarlos, a decirles cosas para que ellos se enojaran y de alguna manera reaccionaran... Mi papá se llamó a silencio después de la Libertadora.

Entrevistadora: ¿en qué sentido?

Entrevistada: En silencio de no provocar. Porque, a ver, su grupo de amigos se dividió. El grupo de parranda de mi papá se dividió, porque estaban los peronistas y los antiperonsitas. Los peronistas fueron perseguidos." ${ }^{31}$

La entrevistada acentúa la dimensión afectiva y emocional de los hechos. Da cuenta de los enfrentamientos y las disputas de orden simbólico e interpersonal, en el seno de una localidad de pocos habitantes que se conocen entre sí. Otros entrevistados también mencionaron la ruptura de los lazos intersubjetivos $\mathrm{y}$, en algunos casos, el silencio que siguió a esas disputas se prolongó durante cuarenta años:

"Mario San Martín: Esto ha cumplido, el 16 de septiembre pasado, 40 años, aún quedan algunos resquemores.

Antonio: Sí, sí. Todavía en la fecha hay resquemores. Hay gente que se dividió para siempre en este pueblo... de la otra gente que les requisó la casa, que los amordazó a todos, a todo el pueblo. No se podía salir a la puerta porque andaban con los fusiles por todos lados (...)"32.

Los relatos citados permiten pensar en los límites porosos entre los silencios, "no-dicho" y el olvido. En ese momento, dada la coyuntura y las condiciones adversas, quienes se identificaban con el peronismo se llamaron a silencio y militantes peronistas activos se retiraron de los espacios públicos. Sin embargo, ese silencio no significaba olvidar. "No decir" sobre cuestiones relativas al peronismo de alguna manera resguardaba la vida y evitaba malos entendidos con conocidos. Ese silencio perduró en el espacio público. Incluso en algunos relatos se deja entrever la transmisión intergeneracional

${ }^{31}$ Entrevista de la autora a Julia, vecina de Malagueño, 48 años, 8 de febrero de 2017.

32 Entrevista realizada por Mario San Martín a Antonio Romero, vecino de Malagueño, Archivo Visión Local, 1995. 
Garbero. Usos del pasado: memorias en torno a la "Revolución Libertadora" en una localidad de la provincia de...

de dichas representaciones o prohibiciones, al menos en el marco familia o en redes pequeñas de sociabilidad afectiva. De hecho, dos vecinas arriba citadas no habían nacido cuando tuvo lugar el golpe de 1955 y sus memorias son producto de los relatos que sus padres les narraron una y otra vez.

En este sentido, Pollak señala que las "las fronteras entre los silencios y "nodicho" y el olvido definitivo y lo reprimido inconscientemente no son estancas; están en perpetuo dislocamiento" (2006, p. 24) y que el silencio responde a razones complejas. También, remarca la importancia de las circunstancias y coyunturas favorables o desfavorables para la circulación y comunicación de determinadas memorias. En suma, evidencia el peso del presente para "modelar" el pasado recordado.

\section{Repercusiones de la "Libertadora" en la historia política democrática del pueblo}

En Malagueño la primera elección de intendente por el voto popular se realizó recién en 1973. Para esa instancia electoral el peronismo llegó profundamente dividido condicionado por los enfrentamientos locales suscitados con el golpe militar de 1955 y profundizados en las siguientes dictaduras. ${ }^{33}$ El peronismo se presentó con dos listas: José Luis Martínez y Juan Bogasky, secretario general de la Asociación Obrera Minera Argentina (AOMA). Una entrevistada nos relataba lo siguiente sobre la identidad peronista y la división a nivel local para la elección de 1973:

"Julia: El peronismo acá en Malagueño era un movimiento único, incluso estaba formada la rama femenina, todo. Y bueno después del ' 55 y durante la década del ' 60 y del ' 70 con golpes militares de por medio, proscripción del peronismo, rearmado del peronismo para las elecciones del '73, el peronismo se divide acá. Y eso también es algo, es otra brecha que está abierta acá en Malagueño, porque es gente que no se olvida de esa división del peronismo.

Entrevistadora: ¿Cómo se divide el peronismo? ¿Entre derecha e izquierda o...?

Julia: No. Eran todos peronistas ortodoxos, eran los que les respondían a Perón. No lo que surgió después. Era 'peronismo peronismo'. Pero se dividen en función de personajes, de líderes locales acá. Lo cual eso genera hasta el día de hoy como mucho resquemor hablar de eso. José Luis Martínez era uno y el otro Juan Bogasky (...)

Entrevistadora: ¿y en qué se diferenciaban estos representantes? Julia: (...) la percepción mía es como que José Luis Martínez

\footnotetext{
${ }^{33}$ Luego del golpe cívico-militar de 1955, las Fuerzas Armadas arremetieron el poder del Estado en 1962 con la destitución del presidente Arturo Frondizi. En 1966 con el levantamiento militar liderado por el general Juan Carlos Onganía que derrocó al presidente Arturo Illia y en 1976 el autodenominado "Proceso de Reorganización Nacional" derrocó a la presidenta María Estela Martínez de Perón e instaló el terrorismo de Estado.
} 
se manejaba como un patrón de estancia en la época de Rosas más o menos, ¿entendés? y Bogasky era peronista, mantenía los ideales del respeto, la igualdad, luchar por el obrero, el darle mejor calidad de vida, pelear por mejor calidad de vida. Martínez tenía ideales personales" ${ }^{34}$.

En el relato de la entrevistada aparecen ciertas representaciones sobre qué define al peronismo, las cuales van a intervenir en la conceptualización que realizará sobre otros aspectos del pasado reciente argentino, por ejemplo la existencia e identidad política de Montoneros -organización armada de origen peronista fundada en 1970- y la actuación militar en la localidad. Besoky (2013, p. 8-9) precisa que "será recién a partir del ' 55 en el marco de la resistencia y a través del nacionalismo histórico que podremos ver la conformación de manera muy embrionaria de un peronismo ortodoxo". Por esto se entendería "un campo ideológico o más bien cultural que rechazaba cualquier intento de vincular al peronismo con el marxismo en cualquiera de sus variantes" (Besoky, 2013 , p. 10). La vecina asocia el término "peronismo ortodoxo" con la lealtad a Perón y "lo que siguió después", las organizaciones de izquierda, son, por lo tanto, calificadas de infiltradas en el Movimiento. Sin embargo, hacer una lectura historiográfica del fragmento de entrevista citado sería forzado y las categorías izquierda, derecha, ortodoxa y revolucionaria pierden cierta especificidad en el relato oral porque la entrevistada termina defendiendo al candidato que los representaba a partir de los valores como la igualdad, la lucha por los obreros, etc.

En 1973 resultó electo Juan Bogasky. A los meses de asumir el cargo, un grupo de seguidores de José Luis Martínez buscaron desestabilizar al intendente en un intento fallido de tomar la municipalidad. Ante eso, un grupo de vecinos se organizó para resistir el eventual golpe, y en ellos estaban presentes los acontecimientos de 1955. Un vecino relató:

"Yo tengo rumores de que se habían buscado armar inclusive, o sea había un lugar donde habían estado este juntando armas para resistir. Porque ellos ya venían con lo del ' 55 , esta misma gente que eran todos contemporáneos obviamente, ¿no cierto? Pero no... no llegó nunca eso. Estoy hablando de gente que en el '55 fue muy maltratada, ¿no cierto? Y lógicamente son todos contemporáneos todos estos muchachos, y que luego con esto bueno, intentaron hacer algo, pero no. Algunos recibieron algunas amenazas muy fuertes. Pero siempre te estoy hablando de un momento que yo no tenía muy claro cómo era el tema. Pero sí sabía qué habían intentado resistir"35.

En julio de 1974, la muerte de Perón -acontecimiento que conmovió el ánimo de gran parte del pueblo- fue la ocasión para pronunciar discursos que apuntaban a comprometerse en un esfuerzo de unidad del peronismo local. Quienes instaban a la unidad

\footnotetext{
${ }^{34}$ Entrevista de la autora a Julia, vecina de Malagueño, 48 años, 8 de febrero de 2017.

35 Entrevista de la autora a Pablo, vecino de Malagueño, 61 años, 13 de marzo de 2017.
} 
Garbero. Usos del pasado: memorias en torno a la "Revolución Libertadora" en una localidad de la provincia de...

sostenían que no podían seguir "subsistiendo esos odios, ambiciones y divisiones que el mismo Presidente Perón se vio obligado a fustigar duramente en su último mensaje". ${ }^{36}$

La gestión de Bogasky fue interrumpida por el golpe militar de marzo de 1976. El gobernador de facto de Córdoba, ex general de brigada Carlos Chasseing, designó a Eulogio Reyna como comisionado Municipal hasta el 21 de mayo de 1976, cuando por decreto $\mathrm{N}^{\circ} 574$ fue designado como intendente Antonio Apolo Prémoli -salteño, médico y casado con una vecina de Malagueño hermana de un coronel del ejército, ya se había desempeñado como intendente designado en 1969- quien ejerció el cargo hasta las elecciones de 1983.

En la transición a la democracia, el peronismo local volvió a organizarse. Nuevamente aparecieron las divisiones pero esta vez José Luis Martínez se "adueñó" -según algunos entrevistados- del justicialismo local y ello llevó a muchos peronistas que no se identificaban con él a no votarlo y a apoyar al representante de la UCR. Así, en 1983, llegó al poder por vía del voto popular el primer y único intendente representante de la UCR a nivel local: Eduardo Piccinini. Su figura era controvertida ya que diversos entrevistados dan cuenta de su participación en las acciones civiles armadas que tuvieron lugar en el golpe de 1955:

"[Piccinini] fue un activo participante político del radicalismo. Él participó del golpe del '55. Tiene la triste fama de haber rastrado el busto de Eva por la plaza: lo ató, lo ató a su Jeep, era muy pro militar. yo tenía cinco años, te cuento lo que se dijo. Sé que él formaba parte de los comandos revolucionarios, con otros ahí, bueno, que se hicieron cargo de la municipalidad $[\mathrm{sic}]^{\prime 3}$.

"Entrevistadora ¿Cómo se llamaba el intendente elegido?

Camilo: Piccinini, está vivo todavía, Fue el primer intendente post golpe [1976]...claro, porque el primero lo habían puesto los milicos [sic] y después vino con Alfonsín, y ya la elección de Alfonsín y él entra en lista radical, con la colaboración de una gran parte del peronismo, va a la elección dividido el peronismo y con esa parte llega él al poder... él fue uno de los que colaboró con esa [Revolución Libertadora]...por supuesto, que no, nunca se supo que le pegaran a nadie pero figuraron ellos como que andaban armados por las calles, colaborando con el golpe." ${ }^{38}$.

El entrevistado se excluye de los votantes peronistas que "colaboraron" para que el referente radical llegue al poder. El tiempo transcurrido no menguan "el secreto a voces" y la reserva con la que se conversa la participación de ese ex intendente en

\footnotetext{
36 "Un hombre, un pueblo", La semilla, julio de 1974, año II, N¹3.

${ }^{37}$ Entrevista de la autora a Raúl, vecino de Malagueño, 65 años, 22 de diciembre de 2015.

${ }^{38}$ Entrevista de la autora a Camilo, vecino de Malagueño, 67 años, 8 de noviembre de 2016.
} 
los comandos civiles armados que amedrentaron a los/as vecinos/as peronistas. El transcurso de 37 años de vida democrática ininterrumpida y la legitimación por gran parte de la sociedad de las luchas de los organismos de derechos humanos son, quizás, las nuevas condiciones políticas y sociales que tornan conflictiva la figura de Piccinini y su trayectoria política. Es un recuerdo ominoso la elección por el voto popular, incluso de una fracción del peronismo, de un protagonista local que se sublevó al orden democrático en 1955 y que intimidó a sus propios vecinos. El proceso de esta investigación permite considerar como indicio que la incomodidad actual guarda relación también con la falta de elaboración colectiva y condena pública de los acontecimientos que tuvieron lugar en torno a la Revolución Libertadora en el ámbito local. En "imagen de sí, para sí y para los otros" (Pollak, 2006, p. 38), estos recuerdos siguen siendo conflictivos y "penosos", de allí su vigencia.

\section{Conclusiones}

Desde una mirada específicamente local, hemos explorado los recuerdos y experiencias en torno al golpe de 1955 en la localidad de Malagueño a partir de las memorias de los vecinos que, en su mayoría, tuvieron la vivencia de los acontecimientos. Esto implicó reconstruir en el ámbito local los hechos que marcaron un período con profundos efectos político-sociales inmediatos y ulteriores.

El golpe de 1955 y la estrategia desperonizadora en Malagueño tuvieron características represivas y violentas. Las memorias vecinales dan cuenta de la persecución, cárcel y amenaza a militantes peronistas y referentes sindicales, allanamiento de viviendas y quema de libros y/o objetos relativos a la identidad peronista. Además, muestran que se reorganizó el espacio público y el uso de la palabra en relación a los temas políticamente correctos: la calle comenzó a estar monopolizada por vecinos que hasta ese momento tenían escasa participación, las actividades militantes relacionadas con el peronismo pasaron a estar prohibidas y a significar una persecución directa y se destruyeron elementos de orden simbólicos peronistas es pos de consolidar un nuevo orden político. El silencio, la censura y el disciplinamiento social fueron aprendizajes sociales funcionales durante las dictaduras posteriores. Aun cuando, las memorias subterráneas locales realzan los caminos sinuosos de la transmisión en el marco de comunidades afectivas y muestran también los límites del trabajo de encuadramiento memorialistico oficial.

La pregnancia del recuerdo de este golpe de Estado está relacionada no solo con el derrocamiento de un líder político sino también con el impacto emocionalafectivo que tuvieron los hechos en la localidad. En primer lugar, el bombardeo en el que Malagueño quedó en el medio de la zona de fuego fue excepcional, único e implicó la movilización de gran parte del pueblo. El "dejar la casa" significó un hecho doloroso y provocó incertidumbre; vaya como ejemplo el pánico colectivo provocado por las explosiones. Luego, la nueva distribución del poder fue una situación propicia para visibilizar las divisiones ya existentes entre peronistas y antiperonistas o radicales pero que en la nueva coyuntura adquirieron matices de violencia, amenazas y persecución. 
Garbero. Usos del pasado: memorias en torno a la "Revolución Libertadora" en una localidad de la provincia de...

Ello se tradujo en rupturas de la trama vincular afectiva interpersonal y social que se prolongaron en el tiempo. Los conflictos fueron vivenciados con intensidad, agravados por la dimensión y las dinámicas de una pequeña localidad en la que todos se conocían. Las historias orales recogidas permiten abrir interrogantes para futuras investigaciones en torno a los vínculos entre emociones y política y las funciones específicas que cumplen las emociones en la construcción de una determinada colectividad (Ahmed, 2015) y en su memoria social.

También, aquellosacontecimientos tuvieron repercusionesen lasrepresentaciones que perduran hasta la actualidad en torno a quiénes son los peronistas, qué es ser peronistas, quiénes fueron "traicioneros y leales". Definiciones que tienen impacto en las configuraciones identitarias políticas vigentes. Tales definiciones resultaron funcionales a la división del peronismo local y no se tradujeron linealmente en el apoyo o preferencia por cierta plataforma política-partidaria en las elecciones del candidato municipal al retorno de la democracia. Entre los vecinos resuena con resquemor la elección como intendente por el voto popular de una de las personalidades que participó activamente de comandos civiles armados de 1955. Sigue provocando profunda aversión el recuerdo de la violencia política vivenciada entre vecinos, familiares y conocidos, y, la figura de ese intendente condensa la contradicción. En conjunto, las memorias muestran que la definición de qué y quién es y son peronistas tiene que ver con una performance, son los sujetos en sus haceres dinámicos y cotidianos los que definen dichos conceptos.

Finalmente, se puede sostener que la intensidad de los recuerdos de la Revolución Libertadora la ha transformado en un marco social de la memoria en Malagueño, en tanto recuerdo sobre el cual se asientan representaciones e ideas que le permiten a los/ as vecinos/as comprender no sólo aquello que sucedió sino también, fragmentos de la actualidad política local y explicar otros hechos de violencia política acontecidos en el pasado reciente de la localidad.

\section{Fuentes}

La Semilla. (julio, 1974). Un hombre, un pueblo, pp. 1.

La Voz del Interior. (17 de septiembre, 1955), pp. 3.

La Voz del Interior. (20 de septiembre, 1955).

Los Principios. (17 de septiembre, 1955). El levantamiento en nuestra ciudad.

Los Principios. (19 de septiembre, 1955). Los civiles en la calle.

Sincich, S. (28 dejulio, 2009). MalagueñoCumple 123 años. Infoguía Malagueño. Recuperado de: http://www.infoguiamalagueno.com.ar/noticias-detalle.php?noticia $=54$

Programa de televisión Malagueño hacia el 2000 (1993, Programa $N^{\circ}$ 63) Malagueño: Canal 4, Mundo visión.

Archivo audiovisual del programa de televisión y periódico local denominado Visión Local. Entrevista de la autora a Raúl, vecino de Malagueño, 65 años, 22 de diciembre de 2015. Entrevista de la autora a Cristina, vecina de Malagueño, 64 años, 30 de julio de 2015. Entrevista de la autora a Camilo, vecino de Malagueño, 67 años, 8 de noviembre de 2016. 
Entrevista de la autora a Julia, vecina de Malagueño, 48 años, 8 de febrero de 2017. Entrevista de la autora a Verónica, vecina de Malagueño, 40 años, 8 de febrero de 2017. Entrevista de la autora a Pablo, vecino de Malagueño, 61 años, 13 de marzo de 2017.

Entrevista realizada por Mario San Martín a Rosario Maldonado de Nieto, vecina de la Malagueño, para el programa de televisión "Malagueño hacia el 2000”, 1993. Entrevista realizada por Mario San Martín Amanda Fioramonti de Orazi, vecina de Malagueño para el programa de televisión "Malagueño hacia el 2000”, 1993.

Entrevista realizada por Mario San Martín a Antonio Romero, vecino de Malagueño, Archivo Visión Local, 1995.

Entrevista realizada por Mario San Martín a Miguel Jorge Della Vedova, vecino de Malagueño, Archivo Visión Local, 1995.

Entrevista realizada por Mario San Martín a Rufino Moreno, vecino de Malagueño, Archivo Visión Local, 2002.

\section{Referencias bibliográficas}

Ahmed, S. (2015). La política cultural de las emociones. Ciudad de México: Programa Universitario de Estudios de Género de la UNAM.

Bertotti, M. C. (2014). La construcción social del espacio "entre" Los Centros Clandestinos de Detención y los territorios sociales aledaños. XI Congreso Argentino de Antropología Social (pp. 1- 18). Rosario: Facultad de Humanidades y Artes de la Universidad Nacional de Rosario.

Besoky, J. L. (2013). "La derecha peronista en perspectiva". Nuevo Mundo Mundos Nuevos, Cuestiones del tiempo presente, Recuperado de http://journals. openedition.org/nuevomundo/65374.

Blanco, J. (2014). “1955, golpe de Estado en Córdoba (Argentina): las limitaciones intrínsecas de la estructura peronista local ante el fortalecimiento preventivo de la Iglesia". Secuencia, 89, 143-161.

Balandier, G. (1994). El poder en escenas. De la representación del poder al poder de la representación. Barcelona: Paidós.

Bourdieu, P. (1985). ¿Qué significa hablar? Economía de los intercambios lingüísticos. Madrid: Akal.

Da Silva Catela, L. (2010). Pasados en conflicto. De memorias dominantes, subterráneas y denegadas. En E. Bohoslavsky, M. Franco, M. Iglesias \& D. Lvovich, Problemas de historia reciente del Cono Sur. Volumen I, (pp. 99-123). Buenos Aires: Prometeo Libros.

Escudero, E. A. (2018). "La útil presencia del pasado: a propósito de los años de la «Revolución Libertadora» en una ciudad del interior de la Argentina (19551958)". Historia y Memoria, 16, 249-280. Recuperado de: https://doi. org/10.19053/20275137.n16.2018.7167

Halbwachs, M. (2004). Los marcos sociales de la memoria. España: Anthropos.

Halbwachs, M. (2011). La memoria colectiva. Buenos Aires: Miño y Dávida Editores.

Huyssen, A. (2001). En busca del futuro perdido. Cultura y memoria en tiempos de globalización. Buenos Aires: Fondo de Cultura Económica de Argentina. 
Garbero. Usos del pasado: memorias en torno a la "Revolución Libertadora" en una localidad de la provincia de...

Instituto Nacional de Estadística y Censos (2010). Censo Nacional de Población, Hogares y Vivienda de la Provincia del Chaco. Buenos Aires: INDEC.

Jelin, E. (2002). Los trabajos de la memoria. Madrid y Buenos Aires: Siglo veintiuno editores. Lorenz, F. G. (2002). ¿De quién es el 24 de marzo? Las luchas por la memoria del golpe de 1976. En E. Jelin (comp.) Las conmemoraciones: las disputas en las fechas "in-felices", (pp. 53-100). Madrid: Siglo veintiuno editores.

Merlino, A. (2012). Investigación cualitativa y Análisis del discurso. Buenos Aires: Editorial Biblos.

Nora, P. (2008). Les lieux de mémoire. Montevideo: Ediciones Trilce.

Olick, J. K. \& Robbins, J. (1998). Social Memory Studies: From "Collective Memory" to the Historical Sociology of Mnemonic Practices. Annual Review of Sociology, 24, 105-140. Recuperado de: https://doi.org/10.1146/annurev.soc.24.1.105

Pécora, G. (2011). Vencedores y vencidos: breve crónica de "La Libertadora” en Río Cuarto. En E. Escuedero \& R. Camaño, Del tiempo del primer peronismo en Río Cuarto. Aproximaciones desde la Historia, (pp. 229-266). Córdoba: Ferreyra editor.

Pécora, G. (2016). “La desperonización en Río Cuarto 1955-1956: ¿acciones dictatoriales o civilidad “democrática”?". Historia Regional, 35, 35-49.

Pollak, M. (2006). Memoria, olvido, silencio. La producción social de identidades frene a situaciones límite. La Plata: Ediciones Al Margen.

Portelli, A. (1991). Lo que hace diferente a la Historia Oral. En D. Schwarzsten (comp.), La Historia Oral (pp. 36- 51). Buenos Aires: CEAL.

Rabotnikof, N. (2007). Memoria y política a treinta años del golpe. En C. E. Lidia, H. Crespo \& P. Yankelevich (eds.), Argentina 1976. Estudios en torno al golpe de Estado (pp. 259-284). México: El colegio de México.

Ricoeur, P. (1999). La lectura del tiempo pasado: memoria y olvido. Madrid: Arrecife Producciones.

Sincich, S. (2002). La Tierra Blanca. Historias de vida en voz alta. Córdoba: S.I.C.

Spinelli, M. E. (2011). La desperonización. Una estrategia política de amplio alcance. Historiapolitica.com. Recuperado de http://historiapolitica.com/datos/ biblioteca/Spinelli1.pdf

Strauss, A. \& Corbin, J. (2002). Bases de la investigación cualitativa. Técnicas y procedimientos para desarrollar la teoría fundamentada. Colombia: Contus, Editorial Universidad de Antioquia.

Tcach, C. (2003). Golpes, proscripciones y partidos políticos. En D. James, Violencia, proscripción y autoritarismo: 1955 - 1976, (pp. 17- 62). Buenos Aires: Sudamericana.

Tcach, C. (2006). Sabattinismo y peronismo: partidos políticos en Córdoba (19431955). Buenos Aires: Biblos.

Tcach, C. (2012). De la Revolución Libertadora al Cordobazo. Buenos Aires: Siglo veintiuno editores.

Todorov, T. (2000). Los abusos de la memoria. Barcelona: Ediciones Paidós.

Vezzetti, H. (2003). Pasado y presente. Guerra, dictadura y sociedad en la Argentina. Buenos Aires: Siglo veintiuno editores. 
Vieytes, R. (2004). Metodología de Investigación en las Organizaciones, Mercado y Sociedad. Epistemología y técnicas. Buenos Aires: Editorial de las Ciencias.

Yuszczyk, E. (2013). "Los golpes de Estado y los medios periodísticos. Córdoba 1955: Los principios frente a la Revolución Libertadora". Andamios. Revista de Investigación Social, 10, (23), 331-358. 